\section{Methods of enlarging material to the concentration table}

\author{
Jacek Feliks, Magdalena Krawczyk \\ AGH University of Science and Technology, Poland
}

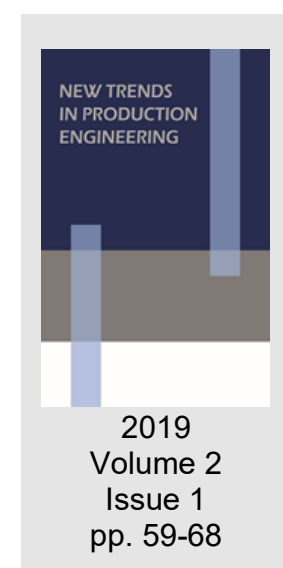

Date of submission to the Editor: 05/2019

Date of acceptance by the Editor: 07/2019

\title{
INTRODUCTION
}

Enrichment is the separation of the feed into grains with a specific mineralogical composition. An example may be the enrichment of fine-grained coal mined by mechanical methods (Bołoz, 2018), i.e. the separation of coal from: sulfur (pyrite) or stone (gangue) in order to obtain the pure material used most often for commercial purposes, energy. In the mining industry, many types of enrichment equipment are used in which the different physical and chemical properties of individual minerals are used. Materials enriched in this way can then be further processed (Feliks, 2015, Feliks, 2017a, Feliks, 2017b, Sidor et al., 2015, Tomach, 2017a, Tomach, 2017b). These properties are specific gravity (density), coefficient of friction, viscosity, etc. An example of this type of equipment are jiggers, heavy liquids, concentrating tables. Concentration tables are one of the oldest oscillatory enrichments with more than a century of tradition. These devices in which the separation of grains is made according to their specific weight (density) during many repeated cycles. These cycles were caused by appropriate drives that induce horizontal movement of the table working surface. Enrichment on concentration tables takes place at the center:

- water - wet enrichment,

- air - dry enrichment.

In the case of dry enrichment, differences in the coefficient of friction are also used. The effect of each of these processes is the fan-shaped material distribution on the table of the concentration Table illustrated in Figure 1.

In Poland, concentration tables are used to enrich zinc-lead ores and in technological lines for enriching glass sands (Łuszczkiewicz et al. 1992, Pilch et al., 1990).

In Austria, concentration tables utilize in the processes of electrotechnical scrap utilization for the separation of plastic insulation sheaths from crushed cables, and for the enrichment of coals and sludge (http: /motive-traction.com.au). 


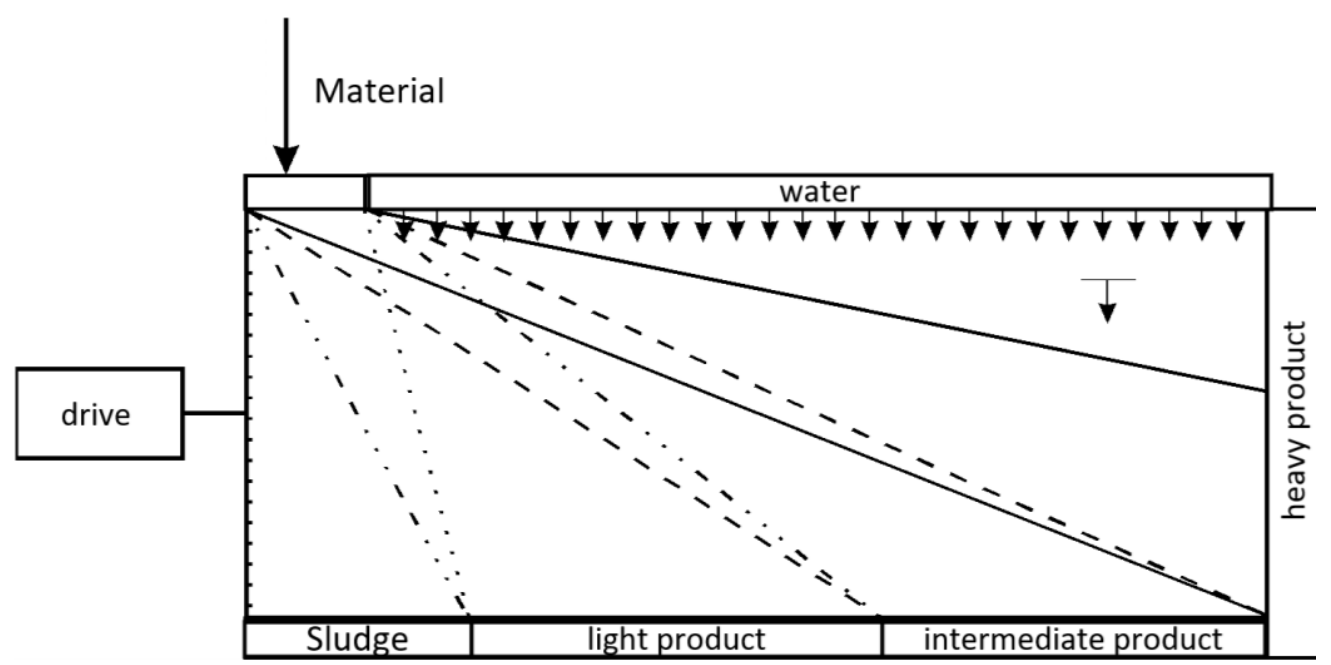

Fig. 1 Scheme of the concentration table with the distribution of material on its surface

In South Africa, which is one of the main exporters of hard coal, fine coal is enriched, among others on concentration tables, which after cost analysis turned out to be the most economical way to enrich small fractions (Blaschke, et al., 1994). In Australia, concentration tables are used to enrich fine carbons (Schubert, 1986). The leading companies compete with each other, constructing ever more sophisticated models of concentration tables. One of them, designed by Wilfley, is the "The Geo" table (http: /motive-traction.com.au). It enables the use of the discussed technology also in remote and inaccessible places with poorly developed infrastructure, eg in Papua New Guinea. An additional advantage of this device is the ability to transport the table with its own power source.

\section{THE PRINCIPLE OF THE CONCENTRATION TABLE}

The most important part of the concentration table is the table top, which is shown in Figure 1. It consists of: a transversely inclined plate, usually in the shape of a rectangle or parallelogram, with a smooth or grooved surface and with supporting spring elements, or rollers or ropes on which it can be suspended. The third element of the concentration table is the drive, whose task is to generate an asymmetric reciprocating movement of the table plate, so that the inertia force from the drive is greater than in the opposite direction, which ensures that the grains move along the table.

The enrichment efficiency depends on the type of drive used. Drives used for concentration tables can be divided taking into account the method of enforcing vibrations on: kinematic and force. As a result of the operation of the drive, a significant difference in the maximum accelerations of the concentration table should be obtained when moving in opposite directions.

The mechanism that has become the standard among the drives of concentration tables is Wilfley's kinematic drive. Its construction is presented in Fig. 2. It belongs to the most numerous group of kinematic and differential drives today. At the same time, it should be noted that, although it is the oldest drive, it is still used in industry. 


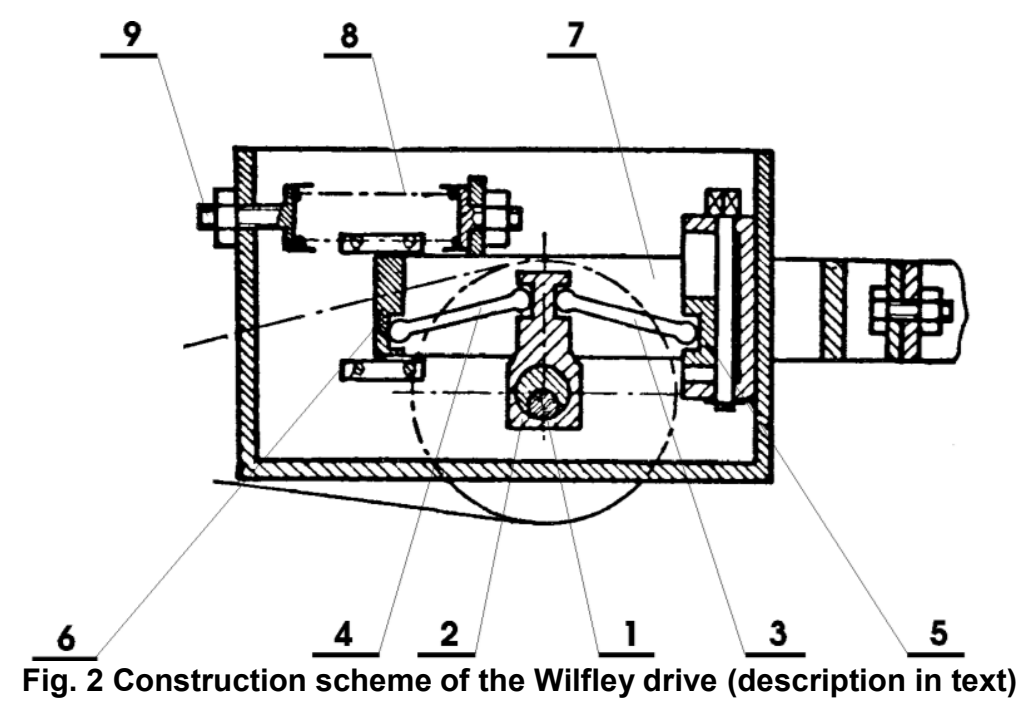

It is described in the following publications (Banaszewski and Blaschke, 1969, Filipowicz, 1992). In the mechanism, the eccentric shaft 1 induces yoke motion 2. In turn, the yoke acting on the blocked block on the one side in the fixed cube seat 5 (used to adjust the pitch of the table), the expansion plate 3 , causes its periodic movement after a circle cut. This movement through the upper part of the yoke 2 is transmitted to the movable expansion plate 4 , the end of which together with the block 6 performs a reciprocating motion. The movement of the cube 6 is transferred to the slider 7 and the table plate. The return movement of the slider is obtained by means of a spring 8 whose voltage is regulated by a screw 9.

The parameter describing the usefulness of the mechanism for its use in the concentration table is the ratio of the maximum absolute values of accelerations s. Acceleration in the direction of the drive will be determined by the symbol, while the symbol will describe the acceleration defining its maximum value in the direction opposite to material movement (Banaszewski, 1997).

$$
s=\frac{\left|a_{1}\right|}{\left|a_{2}\right|}
$$

The second group as to the method of enforcing vibrations are power drives. An example of this type of drive is the inertia-impact table, which is used only in one type of US tables (Battaglia, 1968). Drives of this type allow to obtain a ratio of the maximum absolute acceleration values $s$ above 3 . Another example is the most widespread drive used in Concenco type tables with a four-mass inertial vibrator type 77 and 666 (Donczenko, A.S and Donczenko W.A. 1975). These drives allow to obtain a ratio of the maximum absolute values of accelerations $s$ to 2 . The bifurcated solution is a double-three-speed drive that allows to obtain a ratio of the maximum absolute values of accelerations s to 3 (Feliks, 1999). The enrichment process on the concentration table is explained by two examples of wet and dry enrichment with a fluidized bed. These solutions are most commonly used in industry.

The principle of wet enrichment can be explained in an accessible way using two grains of equal size but with different densities as shown in Fig. 3. 

$\rho_{1}, d_{1}$
$\rho_{2}, d_{2}$

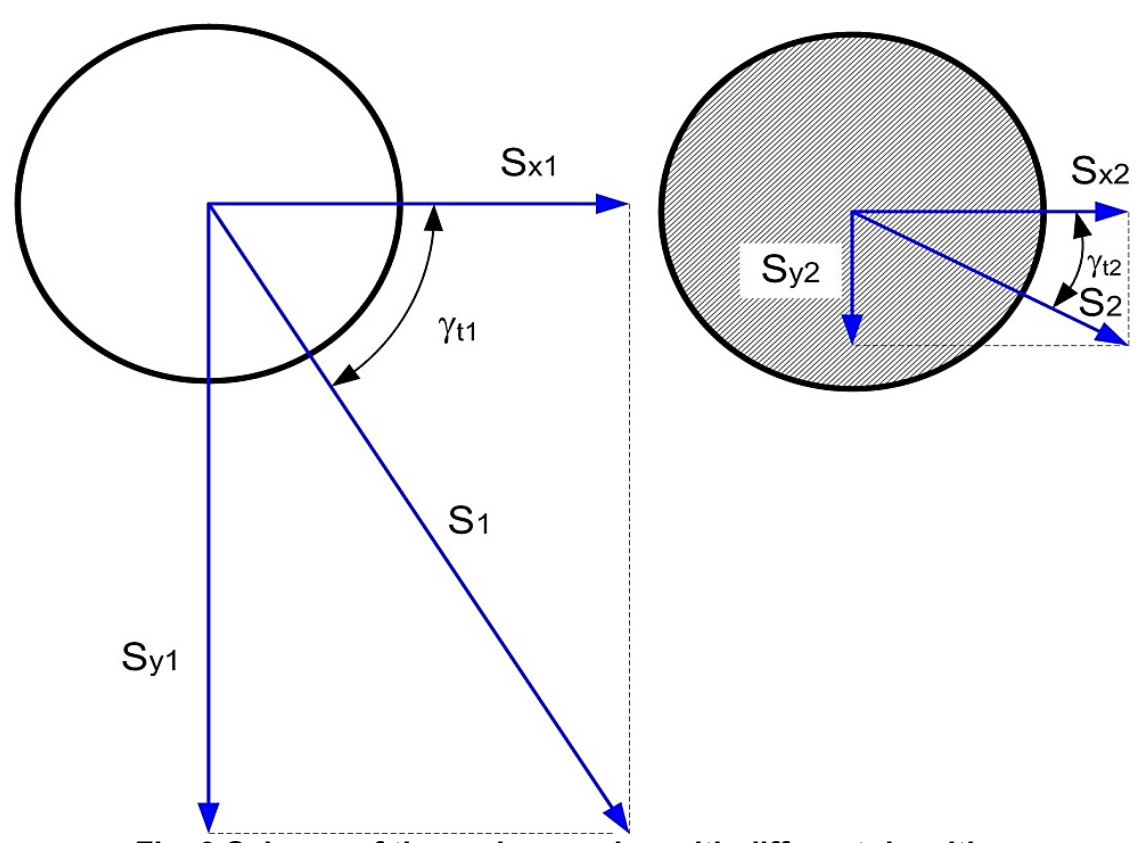

Fig. 3 Scheme of the grains moving with different densities

The feed enriched consists of grains of varying density and size mixed with water, while assuming that they do not have spherical shape and that they do not roll during movement. It is served on a disc in the upper left corner. At the same time, along the long side of the table plate, there is a dispenser that evenly distributes water to the plate.

Due to the fact that the greater inertia force works in the direction from the drive, the considered grains will move to the right by the appropriate sections: $s_{x 1}$ i s $s_{2}$. Inertia forces are proportional to density and depend on, among others from friction coefficients. As a result, assuming that the coefficients of friction between the grains and the substrate are the same, we get the dependence: $s_{\times 1}>s_{x 2}$ or $\mathrm{S} \times 1 \approx \mathrm{S} \times 2$

The movement of the discussed grains is influenced by the pressure of water, which, when flowing down, gives the same thrust forces acting perpendicularly on the assumption that we are dealing with grains with the same cross-sectional areas (diameters). The friction force $\mathrm{F}_{\mathrm{T}}$ acting between the grain and the substrate is greater for grains with higher density $\rho_{2}$.

In connection with the above, as shown in Fig. 3, the component perpendicular to the direction of the table vibrations $s_{y} 1$ by which the grain moves, with a lower specific gravity, under the pressure of flowing water during one cycle is greater than the sy2 component of the other grain having a higher specific gravity. The relationship between components operating in the direction perpendicular to the direction of table vibrations can be presented in the form of dependencies $\mathrm{s}_{\mathrm{y} 1}>$ Sy2.

The result of the combination of these two movements is the resultant along which the grains move. It is of a lower specific gravity $\rho_{1}$ it will move along the resultant vector $s_{1}$ deviated from the level by an angle $\gamma_{t 1}$ whereas grain with a 
higher specific gravity $\rho_{2}$, it will move along the resultant vector $\mathrm{s}_{2}$ deviated from the level by an angle $\gamma_{\mathrm{t} 2}$. When comparing both angles, we notice that $\gamma_{\mathrm{t} 1}>\gamma_{\mathrm{t} 2}$ and therefore, the grain with a higher specific gravity will shift more to the right from the place where the feed is fed compared to grains with a lower specific gravity. The example described explains why a fan-shaped material distribution is schematically shown in Fig. 1 on the real Table.

The presented method of enrichment requires water circuits, which are extremely troublesome due to the very high use of water (much larger amounts compared to the enriched material). Enriched feed is served on the table together with water, and its amount depends on the type of enriched material and its grain size. The volume ratio of water in the feed to the dry material is from 1:1 to 8:1 (Schubert, 1986, Taggart, 1960). In addition to the water served on the table plate for enrichment, the so-called additional water. Its quantity depends on the type and grain size of the feed as well as on the angle of the table plate. For ores, it ranges from $1.5-4 \mathrm{~m}^{3}$ per $1 \mathrm{t}$ of ore. For coal, this range is from 2-4 $\mathrm{m}^{3}$ per $1 \mathrm{t}$ of coal and decreases with the increase of coal grain size. The air enrichment process is similar to the above-described enrichment in a heavy liquid, the difference being that the whole process takes place in a fluidized bed (Blaschke, 2014, Góralczyk, et al., 2016).

The air concentration table is inclined like in the transverse direction. Lowdensity material located on the surface of the fluidized bed tends to slide over this surface and fall continuously due to the force of gravity. Grains of higher density concentrate in the lower part of the fluidized bed and move towards the outlet of waste products through the steering board to the chute of these products, eg stone, high ash coal, shale, coal and stone overgrowths. The disadvantage of this type of solution is forced air circulation causing significant dustiness.

\section{PREVIOUS ATTEMPTS TO USE THE COEFFICIENT OF FRICTION FOR ENRICHMENT}

Classic concentration solutions on concentration tables are used in the process of enriching water pressure. The proportion of water in the enrichment process is very large, and the amount of water significantly exceeds the amount of feed enriched on the concentration table up to eight times (Schubert, 1986, Taggart, 1960). Due to the large amount of water used in the enrichment process, it is necessary to use purifiers, which increase the cost of the process. Therefore, it was decided to carry out research without water by replacing it with another factor. It was decided to continue the work related to the use of friction in the enrichment process on the concentration table (Baran, 1998, Baran, 2000).

The principle of the movement of grains on a concentration table without the use of water was explained with the simultaneous assumption that:

- the diameters of both grains will be the same: $\mathrm{d}_{1}=\mathrm{d}_{2}$,

- their respective masses will meet inequality $\rho_{1}<\rho_{2}$ or $\rho_{1} \approx \rho_{2}$,

- coefficients of friction will meet inequality $\mu_{1}<\mu_{2}$, 
- the seeds do not have a spherical shape and do not roll during movement.

The movement of characterized grains will be described in two steps. The first one will explain the behavior of the discussed grains in the direction of longitudinal inertial forces from the propulsion. In connection with the fact that the greater inertia force is directed in the direction from the drive, the considered grains will move to the right by respectively: $\mathrm{S}_{\times 1}$ and $\mathrm{S}_{\mathrm{x} 2}$. The inertia forces are proportional to the density and depend on the coefficients of friction and many other factors. As a result, we will get dependence $\mathrm{s}_{\mathrm{x} 1}>\mathrm{s} \times 2$.

The next step will explain how the effect on the movement of the model grains from Fig. 4 will have a component related to the tilting of the table. The grain sliding on the sloped plate will overcome the larger transverse component of the road and the smaller the coefficient of friction between the grain and the plate as in Fig. 4.

$$
\rho_{1}, d_{1}, \mu_{1} \quad \rho_{2}, d_{2}, \mu_{2}
$$

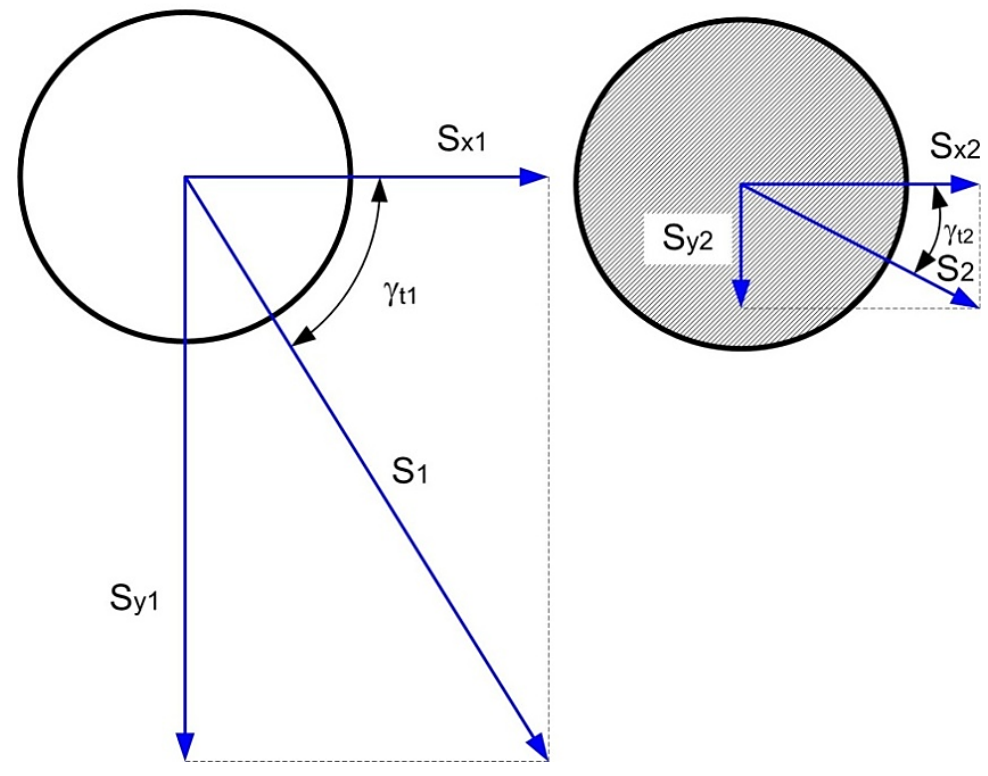

Fig. 4 Scheme of the movement of grains differing in density and friction coefficients between the grain and the plate

Therefore, as shown in Fig. 4, the component perpendicular to the direction of the table vibrations $s_{y} 1$ which grain with a lower coefficient of friction will move over one cycle is greater than the component of the other grain sy2 with a higher coefficient of friction. The relationship between components operating in the direction perpendicular to the direction of table vibrations can be presented in the form of dependencies $s_{y 1}>s_{y 2}$.

The smaller the coefficient of friction the greater the transverse component of the road. As a result of the assembly of these two movements, the grain with a lower coefficient of friction will move along the resultant vector $\mathrm{s}_{1}$ deviated from the horizontal by an angle $\gamma_{t 1}$ whereas the grain with a higher coefficient of friction will travel along the resultant vector $\mathrm{s}_{2}$ deviated from the horizontal by an angle $\gamma_{t 2}$. Comparing the two angles, we note that $\gamma_{t 1}>\gamma_{t 2}$, therefore, the grain 
characterized by a higher value of the coefficient will shift more to the right from the place of feeding the feed compared to the grain with a lower coefficient of friction.

Theoretical considerations of the grain separation process gave rise to the concept that uses enrichment based on differences in friction coefficients between different types of materials and the surface of the concentration table.

\section{CONCLUSIONS}

Concentration tables, despite their disadvantages, still have a wide range of applications in the process of enriching minerals. Wet concentration tables are used in places where there are no problems with obtaining and treating large amounts of water. Air concentration tables have been used in areas poor in water.

Due to the elimination in the process of enriching the share of water, the node of water and sewage management and the lack of a dust removal module, the proposal for the construction of a working device using friction coefficient differences seems to be more economically advantageous.

The Table 1 shows examples of static and kinetic friction coefficients measured on a special constructed device (Fig. 5).

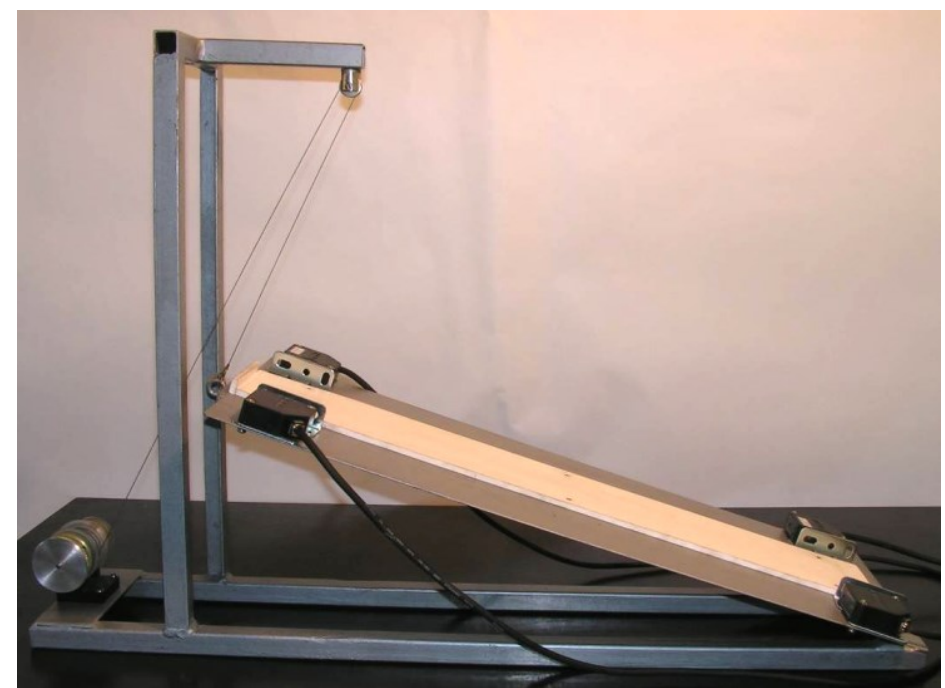

Fig. 5 The device allows testing the static and kinetic friction coefficient

Table 1 List of test results: static and kinetic coefficient of friction between four selected samples and plate

\begin{tabular}{|c|c|c|c|c|}
\hline a sample & $\begin{array}{c}\text { Static } \\
\text { coefficient } \\
\text { of friction } \\
\mu_{\mathrm{s}}\end{array}$ & $\begin{array}{c}\text { Kinetic } \\
\text { coefficient } \\
\text { of friction } \\
\mu_{\mathrm{k}}\end{array}$ & $\begin{array}{c}\text { Ratio of kinetic } \\
\text { friction } \\
\text { to static } \\
\text { friction } \\
\mu_{\mathrm{k} / \mu_{\mathrm{s}}}\end{array}$ & $\begin{array}{c}\text { The difference between } \\
\text { the kinetic friction } \\
\text { coefficient and the static } \\
\text { friction coefficient, \% } \\
\left(1-\mu_{\mathrm{k} /} / \mu_{\mathrm{s}}\right)^{*} 100\end{array}$ \\
\hline $\mathrm{A}$ & 0.255 & 0.22 & 0.863 & 13.7 \\
\hline $\mathrm{B}$ & 0.404 & 0.34 & 0.842 & 15.8 \\
\hline $\mathrm{C}$ & 0.52 & 0.43 & 0.827 & 17.3 \\
\hline $\mathrm{D}$ & 0.62 & 0.53 & 0.855 & 14.5 \\
\hline
\end{tabular}

The analysis of the tests showed the possibility of grain separation using the differences in friction coefficients for individual friction pairs. Preliminary studies 
on the enrichment of the sample material samples on the Wilfley type concentration table at the horizontal table setting showed significant similarities to the previously described theoretical considerations:

1. The mean longitudinal grain speeds increase as the frequency increases.

2. The higher the coefficients of friction, the lower the mean longitudinal speeds of grains.

3. Grains enter the reversing zone depending on the value of coefficients of friction. The higher the coefficient of friction, the higher the frequency at which the grain enters the reversing zone.

The above-mentioned considerations concern the increase of the longitudinal velocity of the grain along with the increase in the frequency of vibrations of the concentration table plate. Comparing the measured and calculated speeds for the same values of friction coefficients, it can be seen that along with the increasing vibration frequency of the table plate, theoretical velocities also increase. Differences between the average longitudinal velocities of individual samples indicate that the coefficients of friction exert a significant influence on the actual grain movement. Samples move at different speeds depending on the type of material. The lower the coefficients of friction, the higher the longitudinal speed of the grain on the table plate.

\section{Nomenclature}

A - symbolic designation of the sample used for testing - material,

$\mathrm{B}$ - symbolic designation of the sample used for testing - plywood,

C - symbolic designation of the sample used for the tests - rubber-stopper,

D - symbolic designation of the sample used for testing - rubber,

$\mathrm{a}_{1}$ - maximum acceleration with positive deflection of the forward movement table, i.e. compatible with the grain movement, $\mathrm{m} / \mathrm{s}^{2}$,

$\mathrm{a}_{2}$ - maximum acceleration at negative deflection of the concentration table, i.e. opposite to material movement, $\mathrm{m} / \mathrm{s}^{2}$,

$\mathrm{d}_{1}, \mathrm{~d}_{2}-$ diameters of model grains, $\mathrm{mm}$

$\rho_{1}, \rho_{2}-$ theoretical grain density (assumed at work), $\mathrm{kg} / \mathrm{m}^{3}$,

$\mu_{1}, \mu_{2}-$ coefficients of friction used to present the grain movement pattern,

$\mathrm{S}_{\mathrm{x} 1}, \mathrm{~S}_{\mathrm{x} 2}-$ components cut off the resultant road, moving on the plate of the concentration table, grain, $m$,

$\mathrm{s}_{\mathrm{y} 1}, \mathrm{~s}_{\mathrm{y} 2}$ - components of the ordinates of the resultant road, moving on the table of the concentration table, grains, $\mathrm{m}$,

$\mathrm{s}_{1}, \mathrm{~s}_{2}-$ the distance the grain travels, $\mathrm{mm}$.

\section{REFERENCES}

Baic, I., Blaschke, W., Góralczyk, S., Szafarczyk, J., Buchalik, G. (2013). An ecological method of removing impurities from waste rock from hard coal mining. A quarterly of the Krakow Technical Society No. 166, Kraków.

Banaszewski, T. (1997). Maximum asymmetry of accelerations with a double-mass dual-torque vibrator. Kwartalnik AGH, Mechanika z. 4, vol. 16.

Banaszewski, T., Blaschke, J. (1969). Wilfey propulsion kinematics. Zeszyty Naukowe AGH, No. 224, Electrification and Mechanization of Mining and Metallurgy, No. 33

Baran, J. (1998). The use of wheeled vibration decks for recovering copper from shredded power cables. Zeszyty Naukowe Politechniki Śląskiej, z. 238, Gliwice. 
Baran, J. (2000). Attempts to split copper and isolation from fragmented power cables on a straight line oscillation. Zeszyty Naukowe Politechniki Śląskiej, z. 245, Gliwice.

Battaglia, A. (1968). Machines for mechanical processing of minerals. Part 2, hydromechanical equipment. PWN, Cracow.

Blaschke, W. Mokrzycki, E. Shan, Z. (1994). Economics of hard coal processing. In International coal-processing congress. T. 5, Krakow.

Bołoz Ł., Midor K. (2018). Process innovations in mining industry and effects of their implementation presented on example of longwall milling heads, Acta Montanistica Slovaca, 23(3), pp. 282-292.

Donczenko, A. S. Donczenko, W. A. (1975). Mechanical expedition mechanic pudoobogatitielnoj fabrika. Niedra, Moscow.

Feliks J. (1999). The asymmetry of accelerations of the triply two-mass inertial table vibrator, Kwartalnik AGH, Mechanika Vol. 18 z. 4 pp. 475-482.

Feliks, J. (2015). Granulation of dolomite and limestone in the vibratory granulator. Przemysl Chemiczny; Vol. 94 nr 5, pp. 771-773.

Feliks, J. (2017a). Pelleting of fine-grained wastes from rock aggregate mines for the needs of remineralisation of soil. Przemysl Chemiczny. Vol. 96, nr. 9 pp. 18601863.

Feliks, J., Mazur M. (2017b). Safety systems against metallic contaminations in feed material, SGEM2017: 17ltextsuperscript $\{$ th\} international multidisciplinary scientific geoconference: science and technologies in geology, exploration and mining: conference proceedings. Vol. 17 iss. 11, Geology mineral processing. STEF92 Technology Ltd., pp. 1043-1050.

Feliks J., Klojzy-Karczmarczyk B., Wiencek M. (2018). Granulating coal sludge and their mixtures to improve transport properties. Zeszyty Naukowe Instytutu Gospodarki Surowcami Mineralnymi i Energią PAN; Vol. 104, pp. 173-188.

Filipowicz, A. (1996). The driving mechanism of Deister type concentration tables. Kwartalnik AGH, Mechanika, vol. 15, item 3.

Filipowicz, A. (1992). Kinematics of the concentration table with Wilfley's drive. Kwartalnik AGH, Mechanika, Volume 15, issue 3.

Filipowicz, A., Feliks, J., Krawczyk, M. (2005). Operation of double single-mass drives for concentrating tables. Conference materials, 4th International Technique of Building Technique, Krynica.

Góralczyk, S. Blaschke W. Kozioł, W. Sobko, W. (2016). The use of FGX air concentration tables for cleaning broken natural aggregates. Mining ScienceMineral Aggregates, vol. 23 (1), 37-46.

Łuszczkiewicz, A. and Kaczmarek B. (1992). Phisicochemical Problems of Mineral Processing. 25, 123-132.

Pilch, W., Stachrsk, J., Sztaba, K. (1990). Investigations and utilization of heavy minerals from Baltic beach sands. Phisicochemical Problems of Mineral Processing. AGH vol. 23 (1), 71-79.

Schubert, H. (1986). Preparation of solid mineral raw materials. Volume II Deustcher publishing house for basic industry, Leipzig.

Sidor, J., Feliks, J. (2015). Granulatory wibracyjne. Przemysł Chemiczny, Vol. 94, no. 5, pp. 767-770.

Taggart, A.F. (1960). Handbook of mineral dressing oras and industrial minerals, J. Wilfley \& sons. New York, London.

Tomach P. (2017a) Study of intensification of the milling process in the vibratory mill, Przemysł Chemiczny; Vol. 96 nr 9, pp. 1893-1897.

Tomach P. (2017b) The process model of the vibratory mill including the impact of the milling process-intensifying element. Przemysł Chemiczny; Vol. $96 \mathrm{nr}$ 12, pp. 2467-2470. 


\begin{abstract}
.
Concentration tables are one of the oldest oscillatory enrichments with over 100 years of tradition. On this type of distribution tables are made according to material mass in many recurring cycles induced by appropriate drives. So-called wet tables are the devices most often used for coal enrichment in Polish mines because this process generates very high costs, high water consumption and pollution of the environment, as well as the need for, among others, water and mud management is increasingly being replaced mainly in areas poor in water by the modern model of the air concentration table - FGX produced in China. The process of enrichment on this type of table itself runs in a manner comparable to the method of wet enrichment with the difference that the FGX is distributed on a perforated plate, in this case we deal with air pollution. Department of Machinery Engineering and Transport's attempts to use the differences in coefficients of friction in over-resonance screens have shown that it is possible effective separation of grains with different coefficients of friction. The article presents a theoretical analysis and presents the results of performed dry enrichment trials using different coefficients of friction. The summary presents the advantages of using the enrichment method using the differences in friction coefficients and test results.
\end{abstract}

Keywords: concentration table, coefficient of friction, enrichment 